\title{
Ser humano, animal y animalidad Novedad y alcance de los Conceptos fundamentales de la metafísica. Mundo, Finitud, soledad 1929/30 de Martin Heidegger
}

\author{
ENRIQUE MUÑOZ PÉREZ \\ Universidad Católica del Maule (Chile) \\ enmunoz@ucm.cl
}

\begin{abstract}
Resumen
El objetivo del presente artículo es mostrar el giro que ocurre en el pensamiento de Heidegger en relación a los conceptos de «ser humano», «animal» y «animalidad» comparando, en primer lugar, el tratamiento que da a los temas en Ser y Tiempo (1927) y en Los conceptos fundamentales de la metafísica. Mundo, finitud, soledad (1929/30). En segundo lugar, pretendo desarrollar algunos alcances de la discusión sobre la animalidad en la interpretación heideggeriana actual. La pregunta que orienta este trabajo es ¿por qué Heidegger rehabilita los conceptos de «ser humano», «animal»y «animalidad» en Los conceptos fundamentales de la metafísica. Mundo, finitud, soledad? Esta pregunta nos permitirá discutir con algunas de las interpretaciones actuales sobre dicha problemática.
\end{abstract}

Palabras clave: ser humano, animal, comportamiento, empatía.

\section{Human being, animal and animality}

Novelty and Scope of the Fundamental Concepts of Metaphysics: World, Finitude, Solitude 1929/30 of Martin Heidegger

\begin{abstract}
The aim of this paper is to show the shift that occurs in Heidegger's thought in relation to the concepts of "human being», «animal》 and «animality» comparing, first, his treatment of the themes in "Being and Time" (1927) and "The Fundamental Concepts of Metaphysics. World, Finitude, Solitude" (1929-1930). Secondly, I explore tendencies in the discussion of animality in Heideggerian interpretations today. The guiding question of our work is why does Heidegger rehabilitate the concept of «human being», "ranimal》 and "ranimality» in "The Fundamental Concepts of Metaphysics. World, Finitude, Solitude?" This question allows us to discuss some of the current interpretations of this problem.
\end{abstract}

Key words: human being, animal, behavior, empathy.

Doctor en Filosofía por la Universidad de Friburgo (Alemania). Profesor Adjunto del Departamento de Filosofía de la Facultad de Ciencias Religiosas y Filosóficas de la UCM. Autor de los libros Der Mensch im Zentrum, aber nicht als Mensch. Zur Konzeption des Menschen in der ontologischen Perspektive Martin Heideggers (2008) y Heidegger y Scheler: Estudios sobre una relación olvidada (2013).

Este artículo desarrolla algunas de las tesis de mi Proyecto de Investigación de Iniciación (2011-2013) que cuenta con apoyo financiero del Fondecyt (Chile) (Proyecto $\mathrm{N}^{\circ}$ 11110127). 


\section{Introducción}

El pensamiento de Martin Heidegger es conocido por ser una de las claves para entender el desarrollo filosófico del siglo XX. El foco de atención recurrente lo constituye la obra fundamental de Heidegger: Sery Tiempo (1927). Sin embargo, un tanto menos atendidas por los intérpretes se encuentran aquellas lecciones que Heidegger dictó pocos años después de publicada su obra principal. Me refiero a textos como Principios metafísicos de la lógica (1928) e Introducción a la filosofia (1928/29). Un caso paradigmático lo constituye, a mi juicio, la lección Los conceptos fundamentales de la metafísica. Mundo, finitud, soledad que Heidegger dictara el semestre de invierno de 1929/30 en la Universidad de Friburgo. En comparación con Ser y Tiempo, hay, a lo menos, dos grandes unidades temáticas que marcan una diferencia relevante con la obra fundamental de Heidegger y se erigen como un lugar recurrente de la interpretación heideggeriana presente, y de aquella que va más allá de ella en la actualidad. Me refiero, entonces, (a) al tratamiento del concepto de «hombre» o «ser humano» (Mensch) ${ }^{1}$, del «animal» (Tier) y de la «animalidad» (Tierheit) en el marco de una nueva aproximación al problema del mundo y (b) la consideración crítica de la biología a partir de los descubrimientos de los científicos contemporáneos a Heidegger.

En el presente artículo, me concentraré fundamentalmente en el primero de estos temas; el ineludible tratamiento del segundo tema será tarea de un próximo trabajo. La pregunta que lo orienta es, entonces, ¿por qué Heidegger rehabilita los conceptos de «ser humano», «animal»y «animalidad»? No pretendo hacer una mera reconstrucción filológica del planteamiento de Heidegger en Los conceptos fundamentales de la metafísica. Mundo, finitud, soledad (1929/30), sino que intentaré discutir, en la medida de lo posible, con algunas de las interpretaciones actuales de esta lección; las mencionadas interpretaciones, me parece, enfatizan solamente una dimensión de la problemática tratada por Heidegger, esto es, la dimensión animal o de la animalidad. Se pierde de vista, a mi juicio, que Los conceptos fundamentales de la metafísica. Mundo, finitud, soledad (1929/30) constituyen un hito en la reflexión heideggeriana sobre el ser humano; en la que la tematización del animal y de la animalidad cumple un mero rol funcional. En otras palabras, sostengo como hipótesis investigativa, que Heidegger desarrolla en la lección Los conceptos fundamentales de la metafísica. Mundo, finitud, soledad (1929/30) un tratamiento novedoso y fundado del

\footnotetext{
1 «Mensch» puede ser traducido como «hombre» o «ser humano»; dado que Heidegger se distancia explícitamente del término «hombre» en Sery Tiempo, opto por la segunda opción.
} 
ser humano, del animal y de la animalidad, enmarcado en una nueva comprensión del problema del mundo. Esta problemática, así planteada, no aparece en la obra principal de Heidegger. Dicha novedad, en especial su estudio de la animalidad, ha inspirado algunas de las interpretaciones más actuales sobre la filosofía heideggeriana tanto en la filosofía anglosajona como en la continental (Derrida, Buchanan, Dastur, Beelman, etc.). Sin embargo, a mi juicio, algunas de esas interpretaciones acentúan demasiado el ámbito de la animalidad, soslayando o evadiendo el tema de lo humano. De este modo, dividiré el presente artículo en tres partes: 1. El tema del ser humano y del animal en Sery Tiempo, 2. El tema del ser humano y del animal en Los conceptos fundamentales de la metafísica. Mundo, soledad y finitud, 3. El tema de la animalidad en Los conceptos fundamentales de la metafísica. Mundo, soledad y finitud y sus alcances en la interpretación heideggeriana actual y 4. Palabras finales.

\section{El tema del ser humano y del animal en Ser y Tiempo}

El punto de partida de este trabajo se encuentra en uno de los parágrafos más conocidos de Ser y Tiempo, me refiero específicamente al \$10. En dicho parágrafo, Heidegger delimita la analítica del Dasein frente a la antropología, la biología y la psicología. Esto es, frente a la pregunta por el ser humano, por la vida en general y por la conducta humana. La crítica a la antropología es ampliamente desarrollada por Heidegger. Menos espacio ocupa sus referencias a la biología y a la psicología. Presentaré, a continuación, la crítica de Heidegger a la antropología y a la biología para mostrar, por un lado, el distanciamiento ante el concepto de «ser humano»y, por otro lado, sus aprehensiones ante la biología en Ser y Tiempo, dominada por la discusión entre mecanicistas y vitalistas. Por último, mostraré los escasos pasajes donde Heidegger menciona la noción de «animal».

En el $\$ 10$ de Ser y Tiempo, Heidegger recorre todo el espectro de la antropología filosófica o «antropología tradicional» como él la denomina. Esto es, hace referencia tanto a la antropología clásica y a la cristiana, como a la moderna y a la contemporánea. En el marco de esta descripción histórica, formula Heidegger su crítica a la antropología filosófica, relativa a la insuficiencia ontológica con que ésta ha tematizado al «ser humano». De este modo, Heidegger reconoce ya en la

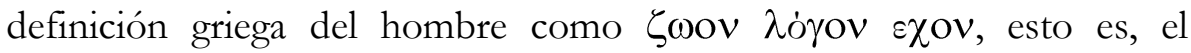
conocido giro «animal racional», una comprensión errónea: el «ser humano» es una noción que es entendida como a algo que «está-ahí» 
(Vorbandensein) o que «se encuentra delante» (Vorkommen) (Heidegger, 1997: 73). En otras palabras, el ser humano ocupa el mismo nivel ontológico que la planta, el animal y los objetos, puesto que es comprendido a partir de la ontología de la sustancia, esto es, a partir de la ontología clásica. Esta comprensión del ser humano tampoco fue superada por la interpretación teológico-medieval, puesto que ella siguió utilizando en su quehacer comprensivo los medios propios de la ontología clásica².

Del mismo modo, el análisis de Heidegger identifica esta dificultad en la antropología moderna. Lo anterior, porque en la filosofía moderna no se cuestiona el estatus ontológico de la subjetividad ${ }^{3}$. Más aún, la noción misma de sujeto posee un importante lastre que Heidegger

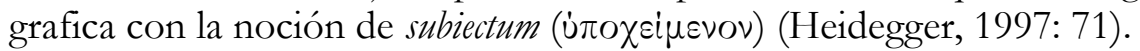

Ya en el período histórico más cercano a Heidegger, esto es, bajo la influencia del historicismo y de la fenomenología, nuevamente es posible apreciar la insuficiencia ontológica con que se estudia al «ser humano». El análisis heideggeriano recae sobre los trabajos de Bergson, Dilthey, Husserl y Scheler. Particularmente en estos dos últimos casos, si bien reconoce Heidegger el valor de las investigaciones husserlianas y schelerianas sobre la persona, sustenta su crítica en una falta de reflexión acerca de la determinación ontológica de su modo de ser (Heidegger, 1997: 73).

Por otro lado, en relación a la biología, Heidegger hace dos críticas importantes en el \$10: una de carácter general y la otra específica. La general, afecta también a la antropología y a la psicología. Ellas «yerran el verdadero problema, el problema filosófico» (Heidegger 1997:71). Es decir, dichas disciplinas deben, a juicio de Heidegger, pensar su fundamento ontológico: pensar el ser del ser humano o pensar el ser de la vida.

2 «2.El otro hilo conductor para la determinación del ser y la esencia del hombre es

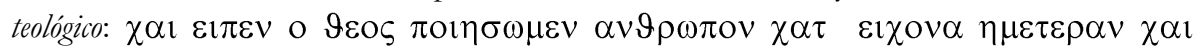
$\chi \alpha \vartheta$ o $\mu 1 \omega \sigma \imath v$, faciamus hominem ad imaginem nostram et similitudinem nostram. La antropología teológica cristiana alcanza, a partir de aquí y con la simultánea recepción de la definición antigua, una interpretación del ente que llamamos hombre. Pero, de la misma manera como el ser de Dios es interpretado ontológicamente con los medios de la ontología antigua, así también, y con mayor razón, el ser del ens finitum» (Heidegger, 1997: 74).

3 «Ambos hilos conductores se enlazan en la antropología moderna con la exigencia metodológica de partir desde la res cogitans, la conciencia, la trama de las vivencias. Pero, en la medida en que también las cogitationes permanecen ontológicamente indeterminadas o se las considera, una vez más, inexpresa y 'obviamente' como algo 'dado' cuyo 'ser' está fuera de todo cuestionamiento, la problemática antropológica queda indeterminada en sus fundamentos ontológicos decisivos» (Heidegger, 1997: 74). 
La afirmación específica de Heidegger sobre la biología se encuentra al final del citado parágrafo. Allí él sostiene que en el orden de su posible comprensión e interpretación, «la biología como 'ciencia de la vida' se funda en la ontología del Dasein, aunque no exclusivamente en ella» (Heidegger 1997:74-5). La vida es un modo peculiar de ser, pero esencialmente sólo accesible en el Dasein. La biología, en consecuencia, no podría darnos una explicación fundamental de la vida.

Este último tópico es posible identificarlo en otras breves, pero importantes referencias a la biología en otros pasajes de Ser y Tiempo (Heidegger, 1997: 268 y 269). Por ejemplo, la referencia que hace Heidegger en el $\$ 12$ a propósito de la expresión «el hombre tiene su mundo circundante». Dicha expresión sólo tendrá sentido, a pesar de los esfuerzos de biólogos como K. E. von Baer, si se deja orientar por la estructura ontológica del Dasein. Por último, en el $\$ 3$ se encuentra el más productivo de los comentarios de Heidegger, puesto que anticipa, en líneas generales, las investigaciones que desarrollará más adelante. De este modo, en el mencionado parágrafo Heidegger revisa el estado de las ciencias de su época. En el caso de la biología, afirma él, se produce un despertar que busca ir más allá de las definiciones de «organismo» y «vida» establecidas por el mecanicismo y el vitalismo (Heidegger, 1997: 33). En otras palabras, Heidegger ya es consciente en la época de Ser y Tiempo de que para estudiar el problema de la «vida» y del «organismo» es necesario abrirse a los nuevos avances de la investigación biológica como los de Jakob v. Uexküll, que ocuparán un lugar central en Los conceptos fundamentales de la metafisica. Mundo-finitud-soledad (Heidegger, 1997: 84).

Finalmente, me resta presentar los escasos pasajes donde Heidegger se refiere explícitamente al «animal» en Ser y Tiempo. La noción de «animalidad» simplemente no aparece en la obra fundamental de Heidegger.

Así, el término «animal» aparece escasamente en Sery Tiempo, esto es, únicamente en los parágrafos $\$ 15, \S 42, \$ 49$ y $\$ 68$. En el primero de los casos, la referencia de Heidegger al «animal» se desarrolla en el marco del análisis de la circunmundaneidad y de la mundaneidad en general; particularmente, Heidegger se ocupa del trato o del habérselas con las cosas del mundo. A juicio de Heidegger, este ente no es el objeto de un conocimiento teorético del mundo, sino que «es lo que está siendo usado, producido, etc.» (Heidegger 1997:95). El tema que concentra la atención de Heidegger, es sabido, es el «útil» (Zeng), cuyo modo de ser es el «estar a la mano» (Zubandenheit). Con todo, sostiene Heidegger, lo a la mano tiende a retirarse. Lo que nosotros efectivamente nos encontramos es la obra misma, lo que en cada caso tiene que ser producido; en la obra es donde el útil comparece. Y es en el marco de esta descripción donde 
Heidegger tematiza la noción de «animal». La obra, «no es tan sólo empleable para..., sino que el producir mismo es, siempre, un empleo de algo para algo» (Heidegger 1997: 98). Es decir, hay una remisión de material a material. Una obra, por ejemplo un sillón, está necesitada del cuero, del hilo, de la madera, de los clavos, etc. El cuero, a su vez, es producido a partir de pieles. «Éstas se sacan de animales que han sido criados por otros. En el mundo hay_también animales que no son de cría, y en la misma crianza ellos se producen en cierto modo por sí mismos». (Heidegger 1997: 98) En otras palabras, el animal no es más que uno entre los muchos entes a la mano como lo son las plantas, el martillo, el alicate o el clavo. No se esboza aquí, por ejemplo, la diferencia entre el tener mundo de la piedra y del animal, como en el caso de la lección del 29/30. No obstante lo anterior, los análisis de Heidegger sobre el útil van a ser retomados por él en Los conceptos fundamentales de la metafísica. Mundo, finitud, soledad, a propósito del esclarecimiento de la esencia de la animalidad.

Una segunda referencia, esta vez marginal, al término «animal» se halla en el tratamiento del tema del «cuidado» (Sorge). La discusión es muy interesante: si el cuidado es el ser del Dasein, es necesario mostrar que ello no es una arbitrariedad de Heidegger, sino que es una aproximación a lo humano desde una perspectiva ontológico-existencial. Heidegger entonces presenta e interpreta una fábula donde el tema esencial es la noción de «cuidado» (cura). Y en ese marco, Heidegger cita a Séneca: «De las cuatro naturalezas que existen (árbol, animal, hombre, Dios), las dos últimas, que son las únicas dotadas de razón, se distinguen entre sí en que Dios es inmortal y el hombre mortal» (Heidegger 1997: 220). Heidegger quiere subrayar, a partir de esta cita, que la perfección del ser humano - el llegar a ser eso que él puede ser en su ser libre- es obra del cuidado. Por cierto, ello está muy lejos de la esencia del animal que, como veremos más adelante, queda preso de su entorno y actúa de un modo perturbado. En otras palabras, el animal para Heidegger no es un ser libre.

La tercera cita sobre el animal se encuentra en el marco del tema de la muerte. La tesis de Heidegger es clara: a la base de la investigación óntico-biológica de la muerte subyace una problemática ontológica, es decir, la pregunta por la esencia ontológica de la muerte. El apartado, en todo caso, donde es mencionado el término «animal» precede esta discusión. Heidegger afirma que la muerte en un sentido amplio es un fenómeno de la vida. También el Dasein se deja considerar como pura vida y él entra entonces, desde una perspectiva bio-fisiológica, en la región de ser que conocemos como el mundo animal y el mundo vegetal. «En este campo se pueden registrar ónticamente datos sobre la duración 
de la vida de las plantas, de los animales y de los hombres» (Heidegger 1997: 267). Es decir, pueden establecerse relaciones entre vida, reproducción, crecimiento y muerte de dichos entes; sin embargo en esos estudios o investigaciones descriptivas, como ya se dijo, la dimensión ontológica de la vida y de la muerte no se discute.

Por último, me resta presentar el pasaje correspondiente al concepto de «animal» enmarcado en el estudio de la temporeidad de la apertura en general. Como es sabido, Heidegger interpreta desde la temporeidad cada uno de los momentos estructurales del Dasein: el comprender, la disposición afectiva, la caída y el discurso. A propósito de la disposición afectiva, Heidegger deja abierta una posibilidad sobre el estudio de la animalidad, que me parece, desarrolla parcialmente en Los conceptos fundamentales de la metafísica. Mundo, finitud, soledad: «La manera como se haya de caracterizar ontológicamente la estimulación y afección de los sentidos en un simple viviente, y cómo y dónde, en general, el ser de los animales, por ejemplo, esté constituido por un cierto 'tiempo', son problemas que requerirían de un tratamiento particular» (Heidegger 1997: 362). Es cierto que Heidegger no estudia la relación del animal con el tiempo, pero dedica largos pasajes de la lección del 29/30 a preguntarse por la relación del animal con el mundo, motivado por la pregunta por la esencia de la animalidad.

A modo de comentario final de este apartado, es posible sostener que los escasos lugares donde emerge la noción de «animal» en Ser y Tiempo, confirman el lugar marginal que la mencionada noción ocupa en la obra fundamental de Heidegger. Como es conocido, su objetivo principal es volver a plantear la pregunta por el ser a partir de la interpretación del ente al que, entre otras determinaciones, le va en su ser su mismo ser y tiene relación con el ser, esto es, el Dasein. La investigación que emprende Heidegger es provisoria, por lo que muchos temas quedan sin ser tratados en profundidad. Cabe preguntarse, entonces, por qué Heidegger aborda un par de años más tarde, con tanto detalle, el tema del animal, de la animalidad y del ser humano en la lección Los conceptos fundamentales de la metafísica. Mundo, soledad, finitud (1929/30). A continuación, me referiré a esta modificación en el pensamiento de Heidegger. 


\section{E1 tema del ser humano y del animal en Los conceptos fundamentales de la metafísica. Mundo, finitud, soledad $(1929 / 30)$}

Un par de años después de la publicación de Ser y Tiempo y en medio de su polémica recepción, Heidegger dicta la lección Los conceptos fundamentales de la metafísica. Mundo, finitud, soledad (1929/30). En este texto Heidegger se aboca a describir, en su primera parte, un estado de ánimo fundamental: «el aburrimiento» (die Langewvile). El mencionado temple de ánimo debiera inspirar el quehacer filosófico en medio de la compleja situación que vive la humanidad a fines de los años veinte del siglo pasado: las consecuencias de la Primera Guerra Mundial, la Gran Depresión, la falta de sentido de la vida, etc. Heidegger distingue, por consiguiente, tres estadios del aburrimiento: «el ser aburrido por algo» (das Gelangweiltwerden von etwas) (Heidegger, 2007: 111), «el aburrirse con algo» (das Sichlangweilen bei etwas) (Heidegger, 2007: 143) y «el aburrimiento profundo como el 'uno que se aburre'» (die tiefe Langeweile als das «es ist langweilig») (Heidegger, 2007: 173). En otras palabras, Heidegger busca subrayar con la descripción fenomenológica de este estado de ánimo fundamental, en especial con el tercer estadio, que la filosofía debe acometer una tarea urgente e ineludible: la «liberación del Dasein en el ser humano» (die Befreiung des Daseins im Menschen) (Heidegger, 2007: 220) $)^{4}$.

Por otra lado, en la segunda parte de la lección, Heidegger une la descripción del temple de ánimo fundamental, el aburrimiento, con las preguntas principales de su concepción metafísica; esto es, la pregunta por la soledad, por la finitud y por el mundo. Heidegger focaliza su atención de modo primordial en esta última pregunta.

Con todo, antes de responderla, él hace la siguiente consideración metodológica. Para responder la pregunta por el mundo, no hay que recurrir a una interpretación fundada en los entes intramundanos, al modo de Ser y Tiempo; tampoco se debe desarrollar una aproximación histórica al concepto de mundo, tal como lo hizo en De la esencia del fundamento (1929), sino que llevar a cabo una «consideración comparativa» (Heidegger, 2007: 227). Heidegger sostiene que «el hombre tiene mundo» (Heidegger, 2007: 227). Empero, ¿qué sucede con los otros entes, por

$4 \quad$ El traductor de Los conceptos fundamentales de la metafísica, Alberto Ciria, traduce el giro «die Befreiung des Daseins im Menschen» como «la liberación de la existencia en el hombre». Si bien es una traducción literalmente correcta, no hace juicio filosófico a la aparición de la mencionada expresión una vez sostenidas todas las críticas de Heidegger tanto a la antropología filosófica como al concepto de ser humano que acaece en Ser y Tiempo y en Kant y el problema de la metafísica. 
ejemplo los animales, las plantas, las cosas materiales, las piedras? Él responde a esta interrogante formulando las tres conocidas tesis: «1) la piedra (lo material) es sin mundo, 2) el animal es pobre de mundo; 3) el ser humano configura mundo» (Heidegger, 2007: 227).

Dicho de otra manera, Heidegger persigue con la discusión comparativa de las tres tesis «delimitar provisionalmente lo que entendemos en general por el título mundo» (Heidegger 2007: 235). Si esto es así, ¿qué es, entonces, el mundo? Al inicio de la segunda parte de la lección, Heidegger nos entrega la siguiente pista. Él sostiene que llamamos «mundo» a «esta amplitud de este 'en conjunto' que se manifiesta en el aburrimiento profundo» (Heidegger 2007: 217). En la disposición afectiva que llamamos «aburrimiento profundo» se nos manifiesta como seres humanos una totalidad, un conjunto o la suma de lo ente accesible al que denominamos «mundo». Sin embargo, esta manifestabilidad de lo ente no es una exclusividad del ser humano, sino que también está al alcance del animal. El punto para Heidegger estriba en que la accesibilidad de lo ente no es la misma en el caso del ser humano que en el animal; ella es «modificable según el alcance y la profundidad del penetramiento» (Heidegger 2007: 244). He aquí un punto decisivo, como veremos inmediatamente, para marcar las diferencias entre el animal y el ser humano. A propósito de este último punto, Heidegger es claro al sostener que él no busca explicar cómo animales y seres humanos se diferencian en algún aspecto específico, sino que su finalidad es esclarecer «qué constituye la esencia la animalidad del animal y la esencia de la humanidad del bombre» (Heidegger 2007: 228). Intentaré sacar más adelante las consecuencias de esta frase de Heidegger.

De este modo, vuelvo sobre el análisis heideggeriano de las tres tesis antes mencionadas. Dicho análisis se concentra principalmente en la delimitación de las diferencias principales entre el animal y el ser humano, en el marco de una nueva aproximación al fenómeno del mundo. Dichas diferencias son tres: el «ponerse en el lugar del otro», el «comportamiento» y la estructura del «en tanto que».

De este modo, Heidegger sostiene, en primer lugar, que la diferencia entre el ser humano y el animal se encuentra en la capacidad que tiene el hombre de «ponerse en el lugar del otro» o "poder transponerse en

Es interesante hacer notar cómo esta «consideración comparativa» heideggeriana entre el hombre, el animal y la piedra, es en gran medida una respuesta ontológica a los planteamientos antropológicos de Max Scheler (El puesto del hombre en el cosmos, 1928) y de Helmuth Plessner (Die Stufen des Organischen und der Mensch, 1928). 
otros» o el «transponerse» (das Sichversetzenkönnen), cuestión que al animal le está vedada. Así lo sostiene Heidegger:

En la medida en que un ser humano existe, en tanto que existente está ya transpuesto en otros seres humanos, aun cuando de hecho no haya ningún otro ser humano cerca. Ser-ahí el ser humano [Da-sein des Menschen], ser-ahí en el ser humano [Da-sein im Menschen], significa por tanto -no exclusivamente, pero sí entre otras cosas- estar transpuesto en otros seres humanos [das Versetztsein in andere Menschen]. El poder transponerse en otros seres humanos como acompañarlos a ellos [Das Sichversetzenkeönnen in anderen Menschen als Mitgehen mit ibnen], a la existencia en ellos, sucede ya siempre en función de la existencia del ser humano... en cuanto existencia. (Heidegger, 2007: 256).

El «ser humano» puede ponerse en lugar de otro «ser humano», puede empatizar y hacer amistad con otro, puede sufrir las penas del otro o alegrarse con sus éxitos; cuestión que al animal no le es posible. Un ejemplo grafica, según Heidegger, las limitaciones del animal: los animales domésticos. El animal doméstico - un perro, un gato o un pequeño conejo- puede comer en un plato, tener una casa o trepar la escalera. «Los animales domésticos los tenemos en casa, 'viven' con nosotros. Pero nosotros no vivimos con ellos, si es que vivir significa ser al modo del animal. No obstante, estamos con ellos. Pero este ser-con tampoco es un coexistir, en la medida en que un perro no existe sino que simplemente vive» (Heidegger, 2007: 261). Heidegger hace presente de esta manera que en el animal no sólo no hay transponibilidad, al modo de los seres humanos, sino que el animal tiene una relación con el mundo que es pobre. Es cierto que el perro trepa las escaleras, el gato come en un plato o que el conejo vive en una pequeña casa, pero ni el perro ni el gato ni el conejo se comportan respecto de la escalera, del plato o de la pequeña casa «en tanto que» (als) tal. En el animal hay, por consiguiente, un tener y no tener mundo.

El animal muestra en él mismo una esfera de la transponibilidad [Versetzbarkeit] a él o, dicho más exactamente: él mismo es esta esfera, que sin embargo deniega un acompañar. El animal tiene una esfera de la transponibilidad [Versetzbarkeit] posible en él, y no obstante no necesita tener eso que nosotros llamamos mundo. [...] El animal tiene algo y no tiene algo. Lo expresamos así: el animal es pobre de mundo, carece fundamentalmente de mundo (Heidegger, 2007: 262).

Por último, es interesante subrayar cómo detrás de esta noción de «transponibilidad» (Versetzbarkeit), se encuentra el modo en que 
Heidegger aborda un tema cardinal de la fenomenología: la «empatía» (Einfüblung).

Por otro lado, Heidegger considera que hay otra distinción fundamental entre el ser humano y el animal: su modo de ser. Al modo de ser del animal lo llama «conducirse» (sich benehmen) y al modo de ser del ser humano lo denomina «comportarse» (sich verhalten). Antes de entrar en el problema mismo, es necesario hacer la siguiente aclaración lingüística. Como bien sostiene Alberto Ciria, el traductor de Los conceptos fundamentales de la metafísica. Mundo, finitud, soledad (1929/30), los verbos alemanes «sich verbalten» $\mathrm{y}$ «sich benehmen» en el lenguaje cotidiano pueden entenderse como sinónimos. ¿Dónde está el matiz que introduce Heidegger? Él aprovecha el sentido del sustantivo «Benommenheit», que se deriva de «sich benehmmen», como «atontamiento», «entorpecimiento» o «perturbamiento» para designar el modo de ser del animal (Heidegger, 2007: 289, véase la nota al pie de página del traductor del texto).

Hecha la breve aclaración lingüística, abordemos el problema que a Heidegger le interesa. ¿Cómo se expresa la diferencia entre el modo de ser del animal y modo de ser del ser humano? Heidegger considera que el conducirse del animal es un «hacer/empujar» (treiben) ${ }^{6}$ y que el comportarse del ser humano es un «actuar» (bandeln). Él nos presenta, en primer lugar, el ejemplo del topo y la lombriz: «La lombriz que huye no aparece simplemente en el contexto de una sucesión de movimientos que parten del topo, sino que buye de éste. Allí no se está desarrollando simplemente algo, sino que la lombriz que huye se conduce como huyente de una manera determinada frente a éste; y éste, el topo, por el contrario, se conduce frente a la lombriz en tanto que la persigue» (Heidegger, 2007: 289). En el fondo, el conducirse del animal es un «ser capaz de» (das Fäbigsein zu) - huir del topo o atrapar a la lombriz- «impulsivo» (triebhaft). Eso significa que el animal, conforme a su esencia, se conduce «en un medio circundante [Umgebung], pero jamás en un mundo [Welt]》 (Heidegger, 2007: 291). En otras palabras, el animal se encuentra encerrado en un anillo, que es su medio circundante, en el que se haya «cautivado en sí» (Heidegger, 2007: 291).

Por el contrario, el modo de ser del hombre es totalmente distinto, es «el comportarse con respecto a» (das Sichverbalten $₹ u$ ), el «hacer» (Tun) o el «actuar» (handeln) en un mundo configurándolo, transformándolo o

\footnotetext{
6 Me parece, en esta ocasión, no del todo afortunada la traducción del verbo «treiben» por «hacer». Como el mismo traductor sostiene «treiben» significa «impulsar», «mover» o, como me parece mejor, «empujar». El sustantivo «Treiben» se puede traducir como «movimiento», «animación» y «actividad». En último término, considero que Heidegger quiere mostrar que tras la conducta animal hay un impulso.
} 
determinándolo. De este modo, en el marco del esclarecimiento de la tercera tesis sobre la consideración comparativa sobre el mundo, expondré la última diferencia fundamental entre el ser humano y el animal: el «en tanto que» (als).

Heidegger ya ha sostenido que el ser humano forma o configura mundo. El animal, en cambio, sólo tiene un acceso limitado al mundo o a lo ente. Heidegger lo ejemplifica de la siguiente manera: «El nido que se busca, la presa que se caza, después de todo no son una nada, sino que un ente, de otro modo el pájaro no se podría posar en el nido ni el gato cazar un ratón, si no fueran ente» (Heidegger, 2007: 324).

Es claro que el animal tiene un acceso concreto a algo que realmente es, «sin embargo, eso es algo que sólo nosotros somos capaces de experimentar y, ostensiblemente, de tener, en tanto que ente» (Heidegger, 2007: 324). Por ello es que en el animal hay un tener y un no tener mundo.

¿Qué quiere decir, entonces, «configuración de mundo»? Heidegger aclara que esta expresión es polisémica. Significa «producir» el mundo, «dar una imagen» suya, «representárselo», abarcarlo, etc. En otras palabras, el ser humano no sólo produce artefactos o construye puentes, sino que forma con otros seres humanos su historia, su tiempo y su época o, si se prefiere, lleva a cabo sus proyectos.

Dicho esto, y haciendo presente que aún le resta interpretar más precisamente el fenómeno del mundo, Heidegger desarrolla inmediatamente la primera interpretación formal del «en tanto que» (als) como un momento estructural de la manifestabilidad del mundo? Heidegger aborda, de este modo, la conexión del «en tanto que» (als) como la estructura de la relación y de los miembros de la relación con la proposición enunciativa.

Dos son, a mi juicio, los pasajes relevantes que me permiten sostener que este tratamiento del «en tanto que» (als) constituye uno de los criterios, en este caso lógico, para diferenciar entre el ser humano y el animal.

Heidegger comienza, en primer lugar, recapitulando lo expuesto. Se ha dicho que mundo es la manifestabilidad de lo ente en cuanto tal en su conjunto. Con esta caracterización emerge algo enigmático: este «en cuanto tal», lo ente en cuanto tal, algo en tanto que algo. $\mathrm{Y}$ he aquí lo relevante: «este 'en tanto que', que es totalmente elemental, es —así

\footnotetext{
7 Hay que tener presente que el tratamiento de Heidegger sobre el tema del «en tanto que» (als) en la lección Los conceptos fundamentales de la metafísica. Mundo, soledad, finitud 1929/30 se enlaza con la comprensión de ser y con el horizonte de aperturidad del mundo en Sery Tiempo, particularmente en el $\$ 32$.
} 
podemos decirlo simplemente- lo que le es negado al animal» (Heidegger, 2007: 346).

En otras palabras, el «en tanto que» (als) marca la diferencia entre lo animal y lo humano. El animal no puede representarse la «piedra como martillo» o tomar su vida "como un todo», al modo como lo hace el ser humano. He aquí la restricción en la penetrabilidad en el mundo del animal.

$\mathrm{El}$ «en tanto que» (als) está conectado, agrega Heidegger, en segundo lugar, con el problema conductor del mundo que está formulado en la tesis: el ser humano es configurador de mundo. Heidegger hace presente que no le interesa partir de una definición arbitraria y dada del ser humano, sino que busca, al menos, cuestionarla. Enfatiza, además, que desarrolla el problema del mundo desde un temple de ánimo fundamental: el aburrimiento. Con todo, cuando se aboca a aclarar el momento estructural del «en tanto que algo», Heidegger se percata que esta tarea no es tan evidente. Normalmente creemos que el «en tanto que» (als) es una relación. Sin embargo, esto que parece obvio, esconde un problema: «La base de la metafísica que hemos caracterizado, y su orientación con arreglo a la verdad de la proposición, aunque en cierto sentido es necesaria, sin embargo, no es originab)(Heidegger, 2007: 349).

Esta no-originalidad ha impedido, sostiene Heidegger, el correcto desarrollo del problema del mundo. En otras palabras, se hace necesario esclarecer la relación entre metafísica y lógica, cuestión que sobrepasa el objetivo del presente artículo.

Me resta finalmente abordar el tema de la animalidad en la lección Los conceptos fundamentales de la metafísica. Mundo, finitud, soledad (1929/30), porque ha despertado una interpretación interesante, creciente y actual.

\section{El tema de la animalidad en Los conceptos fundamentales de la metafísica. Mundo, finitud, soledad y sus alcances en la interpretación heideggeriana actual}

Como ya sostuve, no busco únicamente mostrar en el presente trabajo el contraste entre la obra fundamental de Heidegger y su interesante lección magistral, sino que pretendo también hacerme cargo de uno de los problemas más actuales que se derivan de la interpretación de Los conceptos fundamentales de la metafísica. Mundo, finitud, soledad (1929/30): el tema de la animalidad.

¿Cómo surge entonces esta problemática en la lección? Para desarrollar la consideración comparativa entre la piedra, el animal y el ser humano, Heidegger se concentra latamente sobre la tesis intermedia: el 
animal es pobre de mundo. Él no busca únicamente clarificar la distinción entre el ser humano y el animal, como ya sido mostrado, sino que se pregunta también por la esencia de la animalidad, en el marco del problema del mundo.

De este modo, las descripciones fenomenológicas sobre la animalidad se encuentran, inicialmente, en los parágrafos $\$ 45$ a $\ 48$ de la lección de Heidegger. Él comienza a estudiar con más detención la consideración comparativa partiendo de la ya mencionada tesis intermedia: el animal es pobre de mundo. Heidegger muestra aquí los matices de su acercamiento a la biología y a la zoología. Si bien, sostiene él, la tesis sobre la animalidad «no se basta sin una determinada orientación con arreglo a la zoología y biología en general», necesariamente su confirmación «no la tiene en ellas» (Heidegger, 2007: 237). Más aún, sostiene más adelante que la metafísica aporta «los conceptos fundamentales y las ciencias los hechos» (Heidegger, 2007: 240). Si esto es así, cuál es el significado último de la expresión «el animal es pobre de mundo». Heidegger focaliza su atención, entonces, en la noción de «pobreza»; ella no es entendida en oposición a «riqueza» o bajo el contraste entre «más» y «menos», sino que «ser pobre no significa simplemente no poseer nada o poseer poco o poseer menos que el otro, sino que ser pobre significa carecen (Heidegger, 2007: 245). Esta conceptualización de la pobreza del animal como «carecer» (Entbehren) ha despertado un creciente número de comentarios e interpretaciones, los que se hacen eco, en especial, de las siguientes preguntas de Heidegger: «Pues bien, ¿qué significado tiene el término 'pobreza' en el enlace 'pobreza de mundo'? ¿Cómo hay que entender la 'pobreza de mundo' del animal? ¿En qué sentido es pobre el reino animal? Eso es primeramente oscuro. No podemos decidirlo con una discusión lingüística, sino desde un vistazo de la animalidad misma» (Heidegger, 2007: 246) A pesar de la mencionada oscuridad, Heidegger establece más adelante su comprensión de la esencia de la animalidad. Ello acontece en el parágrafo \58 de la lección del 29/30.

En el apartado anterior, hice presente que Heidegger distingue entre el comportamiento del ser humano y la conducta del animal. Dicha conducta sólo es posible en función del estar cautivado en sí del animal.

El estar-consigo específicamente animal [...], este estar cautivado en sí mismo del animal, en el que es posible toda conducta, lo designamos perturbamiento. Sólo en tanto que el animal está perturbado conforme a su esencia puede conducirse. La posibilidad del conducirse en el modo del ser animal se fundamenta en esta estructura esencial del animal que ahora mostramos como perturbamiento (Heidegger, 2007: 291). 
El perturbamiento o el atontamiento del animal que no puede salir del anillo que lo circunda es, entonces, una estructura esencial del animal o «un momento esencial de la animalidad en cuanto tal» (Heidegger, 2007: 291).

¿Cómo se ha interpretado esta problemática? Las principales interpretaciones que focalizan su interés en la animalidad son las siguientes:

-La recepción francesa: Jacques Derrida. El texto que inspira a los intérpretes francófonos es Del espiritu: Heidegger y la pregunta. Allí, Derrida desde su perspectiva deconstructivista, discute la distancia de Heidegger hacia la noción de «espíritu» e interpreta esta categoría desde un punto de vista político: espíritu y nacionalsocialismo son conceptos incompatibles. Derrida la aplica esta tesis general a la lección Los conceptos fundamentales de la metafísica. Mundo, soledad, finitud, particularmente, a la tesis intermedia: el animal es pobre de mundo. Derrida (1987: 77) comienza su argumentación citando la tesis heideggeriana «el animal carece de mundo, tampoco tiene mundo circundante. Consecuencia inevitable: el animal carece de espíritu, puesto que, acabamos de leerlo, todo mundo es espiritual. La animalidad no pertenece al espirituı. ¿Cuál es la crítica fundamental de Derrida a Heidegger? Principalmente Derrida reconoce en las tesis heideggerianas un residuo de antropocentrismo. La comparación entre el ser humano y el animal es hecha, a su juicio, tomando como medida de ella al ser humano.

Este análisis, obviamente, tiene el interés de romper con la diferencia de grado. Respeta una diferencia de estructuras evitando el antropocentrismo. Pero sigue condenado a reintroducir la medida del hombre por la vía misma que pretendía sustraerla, es decir, por el significado de la carencia o de la privación, que es antropocéntrico o al menos está referido al nosotros cuestionante del Dasein (Derrida, 1987: 81).

Más adelante, Derrida habla de una teleología humanista o antropocéntrica. Para él, se trata «siempre de marcar un límite absoluto entre lo viviente y el Dasein humano, de tomar distancias, no únicamente con todo biologismo y toda filosofía de la vida (y en consecuencia con toda ideología política susceptible de inspirarse en ella más o menos directamente) sino también, como nos recuerda oportunamente Michel Haar, con relación a una temática rilkeana que liga lo abierto con la animalidad» (Derrida, 1987: 87). Precisamente la debilidad que encuentra Derrida en la argumentación heideggeriana, el mencionado antropomorfismo o antropocentrismo, constituye para mí la novedad de 
la lección Los conceptos fundamentales de la metafísica. Mundo, soledad, finitud. En otras palabras, hay que conceder a la lectura derridiana que el tema de la animalidad o de la vida no es tratada en profundidad por Heidegger. Pero ello también se puede decir de otros temas como la corporalidad, la diferencia de género, la indiferencia ante el fenómeno del nacimiento, la intersubjetividad o la ausencia de una interrogación ética. Todos son tópicos que Heidegger deja de lado o esboza insuficientemente. Algo similar acontece con la antropología. Ella no es el objeto de Ser y Tiempo y, más todavía, tanto en la obra principal de Heidegger como en Kant y el problema de la metafísica (1929) se identifican algunas de sus debilidades: insuficiencia ontológica, amplitud e indeterminación (Muñoz, 2007). Por eso mismo sorprende la lección Los conceptos fundamentales de la metafísica. Mundo, soledad, finitud 1929/30; en ella Heidegger despliega una de las dos más ricas exposiciones sobre la esencia de la humanidad del hombre ${ }^{8}$. ¿Cómo entender, entonces, la expresión heideggeriana «esencia de la humanidad del hombre»? En una primera aproximación, no de manera científica, tampoco de manera teológica, por cierto menos de modo antropológico. Se trata de la comprensión ontológica del ser humano, de la apropiación de nuestra propia existencia, de despertar en nosotros como seres humanos aquel temple de ánimo que motiva el filosofar, que está dormido la cultura en que nos desenvolvemos. En otras palabras, me parece que la novedad de la mencionada lección de Heidegger está en un dar un paso más en relación a Ser y Tiempo. Esto es, el ser humano desde su comprensión de ser no sólo se relaciona con los objetos y las cosas, sino que trata con los animales, se vincula con otros seres humanos y, junto con ellos, configura o determina su mundo.

Expuesto lo anterior, continúo con la recepción presente de la lección de Heidegger. Así, la interpretación derridiana de la lección del 29/30, dio inicio a un número creciente de aproximaciones que están motivadas por la temática de la animalidad. Quisiera mencionar, al respecto, dos nombres: Francois Dastur (1995) y Cristian Ciocan (2001). Me parece que la argumentación de Dastur como de Ciocan van en la misma línea, esto es, que las investigaciones desarrolladas por Heidegger en Los conceptos fundamentales de la metafísica. Mundo, soledad, finitud 29/30 tienden a ensombrecer o a no discutir la esencia de la animalidad. Por consiguiente, la observación anterior también se extiende a ellas.

-La recepción norteamericana: Brett Buchanan y Stuart Elden son algunos de los representantes anglosajones que tratan el tema de la

8 Considero que la otra se encuentra en la conferencia inédita Philosophische Anthropologie und Metaphysik des Daseins (1929). 
animalidad. Buchanan pone en el centro de su discusión el concepto de «medio ambiente» (Umwelt, environment), poniendo en discusión la investigación biológica de Uexküll y la reflexión filosófica de Heidegger, Merleau-Ponty y Deleuze 9 . Algunas interpretaciones sobre la animalidad más radicales se encuentran en Stuart Elden (2006). La tesis de Elden es que los análisis de Heidegger siempre acentúan la animalidad como «carencia» (lacking): el animal es pobre de mundo, sin historia, sin manos, sin vivienda, sin espacio. Elden considera que el análisis heideggeriano está sustentado en la tradicional tesis del ser humano como animal rational, particularmente desde el lógos; desde allí es determinada la esencia de la vida animal, que es calificada desde Aristóteles en adelante como álogos. En otras palabras, el ser animal sería producto, a juicio de Elden, de la oposición con lo humano, la medida de todas las cosas. Elden, inspirado en Derrida, abre el espacio para todas aquellas interpretaciones sobre el animal donde se discute acerca de sus derechos. La explicación de este punto de vista sobrepasa la finalidad de este artículo.

- La recepción latinoamericana: Róbson Ramos dos Reis y Juan Manuel Garrido. Por un lado, Ramos dos Reis —especialmente en su libro Fenômenos intermediários e fenomenologia objetiva da vida, aún no publicadodiscute la orientación todavía antropocéntrica de la ontología fundamental que se encuentra en la lección de Heidegger. Cuestiona, además, la debatida tesis que los hombres serían formadores de mundo y los animales (y todos los entes naturales vivos) serían pobres de mundo. Propugna, entonces, el desarrollo de una hermenéutica de la naturaleza viva. Por otro lado, Garrido (2009), aproximándose desde Aristóteles y Derrida, critica la posición ambigua de Heidegger ante el motivo de la vida. La argumentación heideggeriana carecería, a su juicio, de consistencia.

Una vez presentadas algunas de las principales recepciones $\mathrm{e}$ interpretaciones que tratan el tema de la animalidad a partir de la lección magistral Los conceptos fundamentales de la metafísica. Mundo, soledad, finitud 1929/30 desarrollaré finalmente un balance del trabajo propuesto.

\footnotetext{
9 «I have with this study is to examine how three philosophers (Heidegger, MerleauPonty, and Deleuze) each entertain the thought of a single biologist (Uexküll). As noted, many have approached Uexkülls thought, but these three in particular have found in him a compelling case for an ontology of living beings» (Buchanan, 2008: 4).
} 


\section{Palabras finales}

$\mathrm{Al}$ término de este artículo quisiera subrayar la novedad y el alcance de la lección de Heidegger Los conceptos fundamentales de la metafísica. Mundo, soledad, finitud 1929/30. Comienzo por este último punto: su alcance. Sin duda alguna, como demuestra el apartado anterior, las repercusiones de la lección en la interpretación actual sobre y más allá de Heidegger son enormes. De hecho, he presentado únicamente un panorama de éstas. Ellas se extienden desde la identificación de un problema tematizado insuficientemente por Heidegger, como la animalidad o lo vivo, hasta lecturas postmodernas que reflexionan sobre el trato de los animales, defienden los derechos de los animales o hablan derechamente de liberación animal (Singer, 1999). Siendo lo anterior legítimo, me parece que estas perspectivas postmodernas sobre la animalidad son herederas de la destrucción y de la disolución de conceptos tradicionales como «hombre», «ser humano», «yo», «sujeto», «alma» o «humanidad». Dichos conceptos, como es sabido, no serían para algunos defensores de la postmodernidad más que resabios de la antigua metafísica. La pregunta que me surge, entonces, es qué queda de nosotros mismos si ya no somos «ser humano», «yo» o «conciencia». ¿Qué tipo de ente, entonces, somos nosotros mismos? Dicho de otra manera, si bien es plausible el pensar sobre el animal, la animalidad o lo vivo, también me parece necesario seguir pensando lo humano, su esencia, su naturaleza, etc. todavía hoy. Y he ahí el aporte y la novedad de la lección de Heidegger: preguntarse por la esencia de la humanidad del hombre. Enumero algunas de las intuiciones más importantes:

1. Heidegger rehabilita la noción de ser humano y la asocia con el término Dasein en la lección Los conceptos fundamentales de la metafísica. Mundo, finitud, soledad (1929/30), lo que contrasta con la crítica radical a la antropología tradicional y de sus conceptos principales en Sery Tiempo, es decir, «ser humano», «sujeto», «persona», etc.

2. Heidegger desarrolla algunas diferencias entre el ser humano y el animal en la lección Los conceptos fundamentales de la metafísica. Mundo, finitud, soledad (1929/30), que en Ser y Tiempo son inexistentes: el ponerse en el lugar del otro, el comportamiento y el «en tanto que».

3. El denominador común de las interpretaciones actuales sobre la animalidad que se inspiran en la mencionada lección de Heidegger, identifican un resabio antropocéntrico en la contraposición entre ser humano y animal. 
4. A mi juicio, esta última interpretación del pensamiento de Heidegger, pone énfasis en la animalidad, desconociendo los aportes sobre el ser humano que tiene la lección Los conceptos fundamentales de la metafisica. Mundo, finitud, soledad (1929/30). Por ello comparto plenamente la intuición heideggeriana según la cual el animal tiene comportamiento con las cosas, en cambio el ser humano construye conceptos.

Por último, las interpretaciones actuales sobre la animalidad dejan de lado lo siguiente: que las consideraciones comparativas entre la piedra, el animal y el ser humano tienen como punto de referencia una nueva aproximación al problema del mundo. Así lo sostiene Heidegger:

En tanto que intentamos elaborar la esencia de la falta de mundo, de la pobreza de mundo y de la configuración de mundo, nos estamos moviendo en diversas referencias según las cuales lo ente puede estar referido al mundo. Mediante tal interpretación comparativa hay que lograr hacer penetrable la propia esencia del mundo y aproximárnosla tan cerca que primeramente podamos preguntar por ella. Pues el problema del mundo no se da en modo alguno como si se tratara únicamente de una interpretación más estricta y rigurosa de la esencia del mundo, sino que se trata de traer a la mirada por vez primera lo mundado del mundo como un posible tema de un problema fundamental de la metafísica (Heidegger, 2007: 227).

\section{REFERENCIAS}

-Buchanan, B. (2008). Onto-Ethologies. The Animal Environments of Uexkïll, Heidegger, Merleau-Ponty and Deleuze. New York: Suny.

-Ciocan, C. (2001). La vie et la corporalité dans Être et Temps de Martin Heidegger. Studia Phaenomenologica, 1-2, 61-93.

-Dastur, F. (1995). Pour une zoologie privative. Alter. Revue de phénoménologie, 3 , 281-318.

-Derrida, J. (1987). Del espiritu: Heidegger y la pregunta. Valencia: Pre-textos.

-Elden, S. (2006). Heidegger's animal. Continental Philosophy Review, 39, 273-291.

-Garrido, J. M. (2009). L'Animalité de l'être. Le Portique, 23-24, 73-85.

-Heidegger, M. (1992). Die Grundbegriffe der Metaphysik. Welt - Endlichkeit Einsamkeit. Frankfurt: Vittorio Klostermann.

-Heidegger, M. (1997). Ser y Tiempo. Santiago de Chile: Universitaria.

-Heidegger, M. (2007). Los conceptos fundamentales de la metafísica. Mundo, finitud, soledad. Madrid: Alianza Editorial.

-Muñoz, E. (2007). Heidegger y la pregunta por el hombre. Veritas (16), 91-105.

-Singer, P. (1999). Liberación animal. Madrid: Trotta. 
Sumario: Introducción; 1. El tema del ser humano y del animal en Sery Tiempo;

2. El tema del ser humano y del animal en Los conceptos fundamentales de la metafísica. Mundo, finitud y soledad (1929/30); 3. El tema de la animalidad en Los conceptos fundamentales de la metafísica. Mundo, finitud y soledad (1929/30) y sus alcances en la interpretación heideggeriana actual; Palabras finales; Referencias. 